\title{
Room to Play: Tinderbox Collective
}

\author{
Jack Nissan \\ Tinderbox Collective \\ Edinburgh, Scotland \\ jack@tinderboxcollective.org
}

\author{
Luci Holland \\ Tinderbox Collective \\ Edinburgh, Scotland \\ luci@tinderboxcollective.org
}

\author{
Yann Seznec \\ Tinderbox Collective \\ Edinburgh, Scotland \\ yann@yannseznec.com
}

\section{INTRODUCTION}

Room to Play is a multidisciplinary course exploring interactive and digital processes in music, art, performance and game-development. A group of emerging artists, aged 18-25 and from a range of disciplines, worked closely with award-winning musician, game developer and sonic artist, Yann Seznec, and Edinburgh's Tinderbox Collective to develop a series of interactive, sound-based installations and performance ideas. This paper outlines how the project came about, some outcomes from the first course in 2016, and recent developments leading to its second course currently running in 2019 .

\section{BACKGROUND}

Tinderbox Collective: Tinderbox began as an alternative youth orchestra, writing and performing original music by young people, collaborating with local bands and bringing together different genres of music and people with different backgrounds and experiences. It has since grown into a diverse collective of young people, musicians, artists, youth workers, community activists and volunteers, with a number of interweaving programmes - Orchestras, Digital, Community, Schools and Hospitals. These are open to children and young people aged 1030, from complete beginners to young professionals and all levels in between.

Tinderbox's broad approach has always been to balance ambitions for high-quality and experimentation with a drive to be genuinely inclusive and to foster active and creative participation from everyone involved. Its view is that these ambitions can greatly support each other, providing inspiring and powerful learning opportunities that lead to high-quality, original work with diverse influences.

Room to Play: The first Room to Play course took place in 2016 and was funded by Creative Scotland's Open Project fund. The idea was inspired by several factors. First, there seemed to be a growing interest and intrigue around 'gaming' within the arts and creative industries at the time. Second, one of Tinderbox's core members and a co-author of this paper, Luci Holland, was an emerging composer interested in computer games who had recently organised the first Edinburgh Game Symposium, a conference around game audio and composition. Finally, Tinderbox's director had been inspired by a book by Jane McGonigal (2016), whose broad theme explored how some of the design and creative processes involved in building computer games could be applied to 'realworld' environments to make them more engaging and stimulating and to help bring people together. $\mathrm{He}$ was interested in how these ideas might combine with the musical projects, community work and educational approaches within Tinderbox, and whether it might lead to useful new approaches.

The idea emerged to run a 10-week course bringing together emerging artists from different disciplines around digital and interactive processes, from game developers to musicians, visual and other artists. In line with Tinderbox's ethos, the project aimed both to be an educational course and a hands-on, creative project developing and building ideas together. Yann Seznec is a leading game-developer, musician and sonic artist who shares a similar approach, and joined as the lead artist and tutor for the course. He felt that Room to Play could serve as an important platform for demystifying interactive technology and game design, allowing artists and musicians to integrate these techniques into their practice.

\section{GOALS}

The core goals for Room to Play are to grow an active and creative community of emerging young artists from different disciplines, to explore digital and interactive approaches to making work across artforms, and to see what new ideas and crossovers might emerge from this.

To enable this to happen, we felt we needed to build a creative, playful and informal environment 
for the course, offer high quality teaching and new ways of learning, bring together an interesting mix of people, and practically build and exhibit original and exciting work together.

Participating artists in 2016 were also asked what they hoped to gain from the project and their responses are summarised here:

- To meet like-minded people from different disciplines.

- To form new connections and expand creative and professional networks.

- To create an innovative interactive artwork and cross-media collaboration.

- To learn new skills \& work in new creative areas.

- To find new directions and artistic influences.

- To explore how existing skills could be useful for other artists and disciplines.

\section{COURSE STRUCTURE \& EXHIBITIONS}

The structure for the course involved a series of workshops to introduce relevant topics and techniques, alongside the time, space and support for participants to develop and build their own ideas and installations using these techniques. The workshops ranged from game development to basic electronics, sound-design and building midicontrollers.

The course was advertised and people applied with a cover letter and CV. Selected artists attended the course free of charge and received a bursary to help with travel and expenses. In 2016, Room to Play was open to people aged $18-30$ and there were 14 participants. They met once a week for 10 weeks, and developed a series of interactive musical and visual installations over the course. These were publicly exhibited at Hidden Door festival in Edinburgh, and at the Edinburgh Game Symposium in Dundee 2016.

The installations were also brought together with the Tinderbox Orchestra for an improvised performance where audience members played the installations like a set of unconventional instruments with the orchestra. They were also taken to other youth projects and workshops to see if they might help spark some interest and engagement in music.

\section{OUTCOMES FOR PARTICIPATING ARTISTS}

As part of an evaluation of Room to Play 2016, all of the participating artists unanimously 'agreed' or 'strongly agreed' that the project:

- Broadened their professional networks.

- Has led or will lead to new ideas, projects and opportunities.

- Helped them to gain new skills.

- Improved their knowledge \& understanding of different artistic disciplines.

- Helped them gain experience and understanding of working collaboratively.

- Was enjoyable and rewarding.

All artists also said that they would like to develop the artworks produced in the project, and offered positive feedback in their interviews.

\begin{abstract}
"Not only do I have the skills and confidence to start work on new ideas and develop them into bigger projects, I now have fantastic group of friends I can share ideas and collaborate with"

"Such a great opportunity to experience a different creative atmosphere and bring new lessons back to my everyday work."
\end{abstract}

\section{DEVELOPMENT}

The course in 2016 showed a lot of potential. The group of artists gelled very well and kept in touch afterwards. Tinderbox also helped keep people together through occasional workshops, smaller projects and events, such as a metal workshop, a contact microphone workshop and a synth-building project. However, we felt like the project needed a bit more infrastructure and funding at the time to fully build on its momentum and enthusiasm.

Tinderbox is currently in the process of running our second Room to Play course. The format is roughly the same, but with longer days and slightly fewer participants. This time, the course will tie in with the development of a new, year-round 'Tinderbox Lab' - an open-studio with a series of public workshops and technical support. We hope this will create a space for artists to continue making work and exploring ideas together, building on people's learning from the Room to Play course and providing the infrastructure and support for a community like this to grow and develop over time. 


\section{SUMMARY}

Room to Play has so far had a very positive influence on the artists who have been involved. It has also introduced some new creative ideas, techniques and installations that have crossed over into other strands of Tinderbox's work and been well received by public audiences. It has shown a lot of potential but it is still early days and we need to establish the right infrastructure to support a growing and active community of artists across disciplines interested in this work. We look forward to seeing what new ideas will emerge as the project develops.

\section{REFERENCES}

McGonigal, J. (2011) Reality is Broken: Why Games Make Us Better and How They Can Change the World. The Penguin Press, New York. 